Pieter Vermeulen

\title{
Homo Sacer / Homo Demens. The Epistemology of Dementia in Contemporary Literature and Theory
}

\section{Literary knowledge in between the disciplines}

What, if anything, can literature and critical theory contribute to our understanding of dementia? Their contribution to insight into disease and illness has customarily taken place under the rubric of the medical humanities, as that interdisciplinary field has gained institutional visibility since the beginning of the new millennium. In the so-called first wave of the medical humanities (Whitehead and Woods 2016, 1), literature participated in a fairly strict division of labour: while the biomedical sciences provided scientific knowledge, literature figured as a purveyor of affect - as a conduit of feeling that humanises the encounter between the biomedical apparatus and ill bodies and minds. In offering ethical considerations, educational perspectives and personal accounts of illness experience (3), literature functioned less as an independent source of knowledge than as a corrective to the dehumanising drift of science. This relation of complementarity informed two distinct roles for humanities scholarship: either it served as a "positive, pliant and benevolent" helpmate of medicine, or it did duty as its "antagonistic, noisy and opinionated" bad conscience (Viney et al. 2015, 3; similarly Maginess 2017, 6).

Arguably, this bifurcation between antagonistic and conciliatory roles precludes a truly interdisciplinary encounter between literature, critical theory and biomedicine. A recent wave of critical medical humanities scholarship has called for a more "robust commitment to new forms of interdisciplinary and cross-sector collaboration" (Viney et al. 2015, 2). In this new dispensation, the humanities would no longer only supply experience, education and empathy but would recognise that encounters with illness are often marked by negative affects - by "affective distance, and even a lack of care" (Whitehead and Woods 2016, 5). A critical medical humanities would continue to honour "a tradition of antagonistic thinking” (8), but it would mobilise critical ideas for constructive purposes: while "sensitive to imbalances of power, implicit and explicit," such a critical medical humanities would include "activist, skeptical, urgent and capacious modes of making and re-making medicine [. . . ] and hence [medicine's] ability to transform, for good and ill, the health and well-being of individuals and society" (Viney et al. 2015, 3). The emphasis, in this critical or second-wave medical humanities, is 
on "critical openness, plurality and cooperation" (4) - on "creative boundarycrossing in and through which new possibilities can emerge" (Whitehead and Woods 2016, 8). In this new interdisciplinary constellation, literature and critical theory can become more than placeholders for ethics and affect, and can claim recognition as sources of knowledge in their own right.

In the neoliberal university, it seems vital for the survival of literary and critical studies to pursue a more equitable role such as this in the production of knowledge. The shift to a constructive interdisciplinarity, moreover, resonates with developments in research policy and within the field of literary studies itself. As fundamental research in many European countries is increasingly dependent on funding provided by the European Research Council, the ERC's organisation of its research agenda in light of 'grand challenges' and 'missions' all but enforces an interdisciplinary mode of operation, as challenges and missions are defined without explicit consideration for discipline-specific research agendas (even if it is not hard to see how this set-up implicitly privileges the social and hard sciences and forces the humanities to abandon a 'blue skies' approach for a commitment to discipline-external missions and challenges). In the so-called 9th framework programme for research and innovation, which sets the strategic agenda for the ERC's funding decisions in the decade following Horizon 2020, there will likely be little space for humanities research. The one proposed 'grand challenge' that might leave some room for humanities scholarship is called "Citizen Health and Wellbeing." This challenge is linked to a 'mission' titled "Decreasing the Burden of Dementia," which aims to "halv[e] the human burden of dementia by 2030" (Mazzucato 2018, 26). For better or worse, this is the institutional context in which humanities scholarship will likely operate in the near future, and it is a context in which the constructive attitude that proponents of a critical medical humanities promote becomes all but inescapable. In the conversation with other subjects, the humanities should participate as co-creators of knowledge, not just as either critical consciousness or therapeutic humaniser.

This compelled constructiveness dovetails with developments internal to the discipline of literary studies. Recent years have seen a shift away from critique and reading practices powered by suspicion and towards a more affirmative consideration of the affordances and attractions of the literary. Rita Felski's "postcritical reading” (2015, 12), Stephen Best and Sharon Marcus's "surface reading” (2009) and Heather Love's call for "close but not deep" (2010) description (rather than critical interpretation) provide labels for a shared intent to apprehend the potentials of aesthetic objects and the nature of our attachments to them. For these scholars, such an affirmative approach is ultimately more productive than what they (often somewhat reductively) see as the overly negative attitude of poststructuralist critique. They call on literary studies to forego political posturing and to 
reconnect to the field's base commitment to the study of texts and their effects on bodies and minds. As my essay seeks to show, such a return to disciplinary specificity and to the generation of a particular kind of literary knowledge offers a promising avenue to allow literary studies a voice in the larger interdisciplinary dialogue.

This essay, then, makes a double argument about the capacity of literary studies to contribute to an interdisciplinary understanding of dementia. I argue that literary studies has the resources to attend to the repetitions, reductions, indirections and fragmentations that mark the language of dementia. The fragmentary character of the language of dementia is something that decades of attention to trauma testimony and more than a century of modernist complexity have adequately prepared literary studies for; the protocols literary studies have developed for attending to linguistic complexity can be mobilised in the often perplexing and deeply paradoxical encounter with dementia. At the same time, such a disciplinary contribution to interdisciplinary dialogue is often overshadowed by a tendency in a significant strand of literary and cultural representations of dementia to convert the cognitive decline and memory loss associated with dementia into a singular kind of epistemological privilege (even if cognitive and mnemonic decline are only two aspects of the multifaceted reality of dementia). According to this concept, people living with dementia somehow acquire a direct access to a truth that is uncontaminated by the instrumental and logical reasoning to which 'wellfunctioning' (i.e. neurotypical) brains are confined. In the next section, I provide a number of examples of such moves in different literary genres (to underscore that these moves are not genre specific) and argue that they are especially significant in the genre of detective fiction - a genre traditionally committed to the powers of ratiocination. The third section shows how such an elevation of nonneurotypical states of mind as sites of epistemological privilege resonates with a tendency in the field of critical theory to credit particular mental pathologies (paranoia, psychosis, schizophrenia) with exceptional epistemological powers. A cognitive impairment like dementia could become another such paradoxically valorised mental affliction. I turn to the work of Giorgio Agamben, which has been exceptionally influential in theoretical thought in the past two decades, as a particularly important instance of such a rhetorical procedure in order to underline its debilitating abstractness and its inability to address the complex everyday realities of living with dementia. In my final section, I propose an approach to literary fiction dealing with dementia that resists such inflated critical gestures and instead generates disciplinary knowledge that can contribute - although not uncritically - to the interdisciplinary challenge of understanding and improving the lives of people with dementia. 


\section{Blindness and insight in dementia literature}

When we look at some of the ways dementia figures in contemporary fiction, we can see literature negotiate the temptation to accord dementia an awkward epistemological privilege. My examples come from three literary subfields - one highbrow and experimental, one middlebrow and one young adult. I begin with the last. In Norwegian author Johan Harstad's young adult novel 172 Hours on the Moon from 2008, NASA organises a global competition to assemble a crew of three youngsters for a trip to the moon, more specifically to a moon base that was abandoned in the 1970s for lack of resources. All but one of the astronauts die on the trip in strange fights with mysterious doppelgängers. Extremely fast and strong, these doppelgängers are evidently intent on the destruction of humankind. The plot's final horrific twist is the revelation that the one survivor is actually a doppelgänger, who travels to Earth to inevitably wipe out human life. By forcing us unwittingly to inhabit the mind of that destructive doppelgänger, the novel creates a particularly powerful and disturbing experience.

Still, the novel somewhat prepares us for this apocalyptic climax through one character with dementia who, we read, used to work as "a custodian with the highest security clearance at NASA" but whose warnings about the moon trip are not taken seriously in the care home in which he lives, since he is reduced, as the narrator notes, "to a bag with eyes, a box no one really knows where to send" (Harstad 2012, 24). The conclusion to the plot redeems the old man's pronouncements and retroactively qualifies them as visionary prophecies. The ex-custodian's failure to communicate convincingly, in the logic of the novel, comes to stand for a deeper oracular knowledge of the apocalyptic doom that awaits the world. Cognitive attrition, by means of which dementia is represented in this text, is, in short, converted into epistemological privilege.

This move is emphatically part of the novel's generational logic. The novel makes it very clear that the lunar travel competition is a cynical ploy by older generations to revive a disastrous space exploration project from the 1970s and to sacrifice a younger generation in the process. This generational logic, in which a baby boomer generation sells out the welfare state and ruins the planet for generations born after 1980, is a constant feature of Harstad's novels - 172 Hours on the Moon is not the only of his novels to end with planetary collapse (Vermeulen 2017). In this respect, it is significant that in the novel the character living with dementia is called Himmelfarb - a Yiddish name meaning 'colour of the sky' and thus intimating the character's singular capacity to read the signs of the coming apocalypse. Yet in this context of doom and forgetting, the name also inevitably points to the Holocaust - and to a generation of survivors who, unlike the cursed baby boomers, have remembered enough to see and read 
apocalyptic signs. This is something the post-war generation, the novel suggests, has chosen to forget. The trope of dementia, then, points not directly to a fatal forgetting but to a more complex dialectic of remembrance and forgetting: in the plot, dementia paradoxically stands for an act of unforgetting (or an inability to forget), something post-war generations conveniently forget to attend to.

The appeal of dementia as the placeholder of an alternative epistemology is particularly significant for the detective novel, as that genre was traditionally beholden to the force of human ratiocination. A fundamentally conservative genre, traditional ('golden age') detective fiction invites the reader to identify with a rational guide who manages to distil a coherent narrative out of a bewildering array of details and to help isolate and eliminate criminals from society (Porter 1981; Moretti 2005). Detective fiction is then an extended paean to order and reason in which the figure of the detective is tasked to "re-establish sequence and causality" (Porter 1981, 30) and reinscribe the social world as an eminently legible and orderly place. Such exalted claims for the rational powers of the detective seem rigorously incompatible with the symptoms of dementia. This is perhaps nowhere clearer than at the end of Henning Mankell's Wallander series, where, in the ninth book in the series, Mankell decisively signals the end of Wallander's career by showing him, as the novel has it, "descend[ing] into a darkness that some years later transported him into the empty universe known as Alzheimer's disease" (2009, 501; see also Simonsen 2015). No resurrection, then, for Wallander - as there was for Sherlock Holmes when Arthur Conan Doyle gave in to public pressure to continue the Holmes franchise in 1901 after having seemingly killed the character in 1893: "After that," Mankell $(2009,501)$ writes, "there is nothing more. The story of Kurt Wallander is finished, once and for all."

Works that bring dementia to bear on the template of the detective novel, then, point to an ambition to query the model of rationality encoded in the genre. Indeed, there is a more general tendency in dementia fiction to single out individuals who embody ideals of rationality. Examples are Lisa Genova's Still Alice (2007), in which a linguistics professor at Harvard develops early-onset Alzheimer's; Matthew Thomas's We Are Not Ourselves (2014), in which the affliction hits a neuroscientist; or Alice LaPlante's thriller Turn of Mind (2011), which is narrated from the perspective of a neurosurgeon with dementia (see also Martina Zimmermann's essay in this volume). The collision of dementia and intellectual prowess serves to underline the cruelty of the syndrome; yet within the genre of the detective novel, it often serves as an occasion to explore alternative modes of access to truth.

Emma Healey's bestselling 2014 novel Elizabeth Is Missing signals its critique of traditional modes of rationality through its variation on the template of the detective novel. Elizabeth Is Missing offers an exceptionally compelling account of 
the demented mind: half of the novel is narrated by Maud, who moves through different stages of what the reader deduces must be dementia as the story progresses. We are invited to share her disorientation and lack of understanding of events as she finds herself in situations that she, like the reader (since the openings of the chapters all take place in medias res) is at a loss to understand and with which she (again like the reader) needs to learn to cope. Elizabeth Is Missing, in short, is the kind of novel that can contribute to interdisciplinary discussions of dementia: it offers a fictitious internal, first-person perspective that other disciplines count on literature to deliver.

Yet the novel does not fully sustain the modest realism of its evocation of dementia. The chapters focalised through Maud alternate with instalments of a story situated in Maud's youth in the immediate aftermath of the war, when her sister Sukey unaccountably disappeared. The disappearance was never resolved and has, we are meant to infer, remained an open wound throughout Maud's life; in the novel's narrative present, it resonates with what Maud takes to be the (not so) mysterious disappearance of her friend Elizabeth from her house. To the reader's mild frustration, it takes Maud until the end of the novel to remember what her daughter has told her: that Elizabeth has been moved to a hospital. Yet the resonances between the two disappearances in Maud's mind do allow her to solve the old crime. Because the dialectic of remembering and forgetting - instantiated by Maud's dementia - reorganises the information that has remained half buried in Maud's mind for more than half a century, she finally links up the different clues and identifies a particular patch of land where her daughter then digs up Sukey's remains. As Maud says, "It is my fault because I looked in the wrong places, I collected rubbish from everywhere else, and all the time the real things were lying out there, waiting for me" (Healey 2014, 258). It took a cognitive impairment and the dementia-induced reorganisation of Maud's memory to distinguish the rubbish from the clues.

Significantly, the novel presents this solution as the quasi-automatic outcome of non-transparent and mysterious mental processes, not of a more traditional process of ratiocination. Again, dementia seems to hold an exceptional relation to a truth that remains inaccessible to 'normally' functioning brains, and detection and dementia appear to be intimately connected. Katsura Sako (2016, 323-324) has noted that the collaborative nature of the discovery, in which Maud and her daughter both play crucial roles, exemplifies a tendency in contemporary detective fiction by women writers to abandon the authority of the rational individual for more cooperative modes of discovery. Another kind of female intimacy is even more significant. The strand of the novel situated in Maud's youth is haunted by a "mad woman" who roams the streets in despair over the death of her daughter, yet whom the young Maud also believes to hold the knowledge about the 
disappearance of her sister. When the police interrogate the old Maud after the identification of the remains, she explicitly mentions the enabling role played by the mad woman ("It's what the mad woman said" [Healey 2014, 267]). Madness and dementia, that is, both play a role in the revelation of the truth. As Lucy Burke (2017a, 95) has argued, this shows that "the novel arguably retains a residual affinity for the kind of medieval figuration of wisdom in folly that Michel Foucault identifies in Madness in Civilization." Indeed, the novel develops a "fundamentally ethical figuration of both women as agents of truth - almost as the embodiment of a will or drive to truth - insatiable, furious and relentless" (96). The solution at the end of the novel suggests that society sidelines this aberrant yet paradoxically epistemologically privileged perspective at its own peril. Even if the epistemological privileging of dementia, as I have been arguing, is problematic, the marginalising that the novel argues against equally misses the specificity of dementia.

Such an elevation of a particular dementia epistemology is not only a feature of young adult fiction and genre fiction, but also of contemporary experimental writing. The last instalment in British author Will Self's decidedly high modernist trilogy of novels - Umbrella, Shark and 2017's Phone - is a case in point. The trilogy has been described as an "embuggeringly difficult and repetitive stream-of-fractured-consciousness" work (Leith 2017) and as "a brilliant, epic anti-tweet" (White 2017). Phone itself consists of one continuous 600-page paragraph in which "five different free-indirect points of view cycle in different time frames, transitioning without warning mid-sentence” (Leith 2017). The novel begins in the consciousness of the 78-year-old Zack Busner, a retired psychiatrist who is suffering a breakdown in a restaurant. The novel opens with the evocation of a telephone ringing:

\footnotetext{
$\ldots \ldots \ldots$ ! and again $\ldots \ldots \ldots$ ! Two groups of four . . . . . ! on it goes . . . ... . ! insistently persistently . . . . . . . ! not that one hears it quite so much nowadays . . . . . . ! if one does it's a fake - a recording of an old phone . . . . . ! done with a lot of echo ....... ! so's to suggest it's ringing in a largish, darkish hall . . . . . . poorly lit by tall, narrow windows . . . . . ! many little stained panes . . . . . . . ! altogether depicting a square-jawed medieval knight. (Self 2017, 1)
}

The passage conveys what we could call high modernism's hyperrealist ambitions: the attempt to capture the overwhelming and disorienting influx of data and impressions on what Virginia Woolf famously called "an ordinary mind on an ordinary day." In this passage, the sequences of four dots do not mark elisions but reflect the ringing of an old-fashioned phone, which the novel amplifies as part of the information overload beleaguering the contemporary mind. Even the customary diacritical marker of silence, then, has become loud and intrusive. The passage reflects the trilogy's overarching ambition to capture the 
madness of twentieth- and twenty-first-century life and to tap into the imbrication of consciousness and technology.

It transpires that dementia - or, more specifically, Alzheimer's - functions as some kind of master pathology for coping with this madness, as Busner turns out to be experiencing the onset of the condition. In a way that comes remarkably close to the link between dementia and detection in Elizabeth Is Missing, where forgetting enables a better grasp of clues and signs amidst semiotic detritus, Busner reflects that "Alzheimer's itself may be a form of good mental health - after all, what could be saner in a world in which every last particle of trivia is retained on some computer than to . . . forget everything” (Self 2017, 30). Cognitive regression (which is the aspect of dementia this novel foregrounds, even if we know it to be a much more multifaceted syndrome), in other words, appears as a salutary capacity for information sifting. As Self himself said in an interview, "Perhaps dementia is the only sane response to a world in which all information is retained. The individual has to obliterate this overload of data. Alzheimer's becomes the abiding condition of the human subject in a situation of total access to information" (Doherty 2018). The double nature of dementia - as both a form of cognitive regression and a shortcut to insight - is announced in the novel's epigraph, which is taken from psychiatrist R. D. Laing: "These arabesques that mysteriously embody mathematical truths only glimpsed by a very few - how beautiful, how exquisite - no matter that they were the threshing and thrashing of a drowning man" (Self 2017, n.p.). The indifference signalled in the words "no matter" here points to a mismatch between the grandiose claims made on behalf of struggling individuals, "threshing and thrashing," and their lived experience.

\section{Abjection and abstraction: Dementia theory}

The literary tendency to inflate the epistemological promise of dementia resonates with analogous developments in the field of critical theory. The fact that this tendency can be observed in different cultural domains strongly suggests that it taps into a deep societal unease about the dubious ways we deal with dementia, and with people with dementia. Even if the epistemological elevation of people with dementia might be explained as a form of guilty overcompensation, it is important to underline that it is not very helpful in coming to terms with dementia as a social phenomenon. Especially since the rise of poststructuralist theory in the 1970s, the field of critical theory is prone to exploring figures of extremity, whether these are subalterns, cyborgs, posthumanoids or Muselmänner. In this field, the elevation of abjected figures inhabiting the borderlands of mental life is not uncommon: 
think of Deleuze and Guattari's staging of the schizophrenic as a radical and revolutionary nomad who scrambles, decodes and reconfigures the elements of reality in the unrestrained pursuit of desire (2009); think of Fredric Jameson's recognition, shortly after his dismissal of conspiracy thinking as "the poor person's cognitive mapping," that paranoid thought yet constitutes an attempt "to think a system so vast that it cannot be encompassed" by customary categories and perceptions $(1992,2)$; or think of recent claims that psychosis is a productive posture through which we can apprehend the dissociated realities of digitalised finance (De Boever 2018). All these positions seek out postures of mental extremity to find an alternative access to truth.

This rhetorical move, which converts mental distress into a site of truth, is ingrained in critical theory (as well as in the literary imagination, as my examples show). The work of Giorgio Agamben provides a case in point, not least because it is regularly invoked in discussions of dementia and Alzheimer's (and has had a great influence on critical thinking, especially once the aftermath of 9/11 made the timeliness of his work unmistakable). In Homo Sacer, Agamben notoriously identifies the concentration camp as the paradigmatic figure of Western political governmentality. In the very last pages of that book, Agamben introduces the $\mathrm{Mu}$ selmann as "the most extreme figure of the camp inhabitant." The Muselmann, according to Agamben, is "a being from whom humiliation, horror, and fear had so taken away all consciousness and all personality as to make him absolutely apathetic." "Mute and absolutely alone," we read, "he has passed into another world without memory and without grief” (Agamben 1998, 185).

It is not hard to see why descriptions like these have resonated with dementia researchers. Lucy Burke $(2019,5)$ has argued that analogies between the Holocaust - as "the most unspeakable form of suffering" - and dementia are widespread in cultural and journalistic as well as academic registers, and they serve to encapsulate the syndrome's "extreme impact upon personhood." The spectre of the death camp recurs in humanities scholarship on dementia. Anthropologist Lawrence Cohen, for instance, has claimed that dementia provides "a more compelling, or at the least more generative, exemplar" of the paradoxes that mark devalued forms of life - more compelling, that is, than the examples of the Muselmänner and the brain-dead patients that Agamben himself invokes. This is the case, Cohen $(2006,9)$ writes, "given the strong ambivalence that comes to haunt the value of severely demented life" - its uncertain positioning in relation to notions of personhood, autonomy and agency.

While this is a description of dementia one may subscribe to, it misunderstands Agamben's - and much of critical theory's - larger project. This is a project less committed to "strong ambivalence" than to the paradoxes of extremity, less interested in the complex and textured mixture of societal values than in 
the rhetorical affordances of paradox. The rest of the career of the Muselmann in Agamben's oeuvre makes this clear. If he makes only a cameo appearance at the end of Homo Sacer in 1998, in Remnants of Auschwitz, a sequel of sorts published two years later, the Muselmann receives a full chapter that teases out the paradoxes of his existence - his status as "an indefinite being in whom [...] humanity and non-humanity, [. . .] vegetative existence and relation, physiology and ethics, medicine and politics, and life and death continuously pass through each other" (Agamben 2000, 48). This position as a limit figure between the human and the inhuman paradoxically makes the Muselmann an adequate witness to the horrors of the twentieth century. For Agamben, testimony is "an ethos of bearing witness to that for which one cannot bear witness" (Mills 2008, 81). This means that the Muselmänner, rather than the survivors, count as, in Primo Levi's terms, "the complete witnesses" (Agamben 2000, 33) to the Holocaust. Exposure to extreme suffering, in other words, acquires a form of epistemological power. The Muselmann is cast as an ethical figure in order to shift epistemological authority from traditional reason to testimonial truth.

Agamben's Muselmann points to a more general critical proclivity for (mis-) reading immobility and despair as paradoxically appropriate modes of witnessing violence, for seeing inarticulacy as the oblique communication of an unspeakable truth and for celebrating forgetting as an indirect mode of fidelity to the immemorial. When we conceptualise dementia as "the exception inherent in the normative construction of aging," as anthropologist Jessica Robbins $(2008,17)$ does, or when we see it "as the proxy or promise of bare life," as fellow anthropologist Lawrence Cohen $(2006,11)$ does, we underline the proximity of Agamben's reflection on the production of bare life to the phenomenon of dementia. To the best of my knowledge, Agamben uses the term "demented" - demente in Italian only once, and not in the Homo Sacer volumes but in a short essay titled "What Is the Contemporary?” (Agamben 2009, 43-44). In this essay, Agamben puts forward the thesis that in order to capture contemporary life, we need to be able to keep our distance from it: so as not to be blinded by the flashy hyperpresence of the present, we need to cultivate the capacity to see darkness. "The contemporary," Agamben writes, "is he who firmly holds his gaze on his own time so as to perceive not its light, but rather its darkness." Only in this way, Agamben argues, can the contemporary see the "demented grin on the face of his age." Perceiving obscurity, Agamben notes, is not the same as lacking vision - as the neurophysiology of vision shows, the absence of light activates a series of peripheral cells in the retina called "off-cells" (44), and "to perceive [. . . ] darkness is not a form of inertia or of passivity, but rather implies an activity and a singular ability" (45).

Dementia is linked to a paradoxical ability to see darkness and thus to witness the truth. And if, as I suggested above, this notion has become a pervasive 
trope in literature and theory, it is important to underline the problems with such a valorisation of darkness and illness if literary studies is to make a disciplinary contribution to an interdisciplinary understanding of dementia. Of course, putting such intellectual emphasis on representations of dementia has the merit of helping remove the stigma that attaches to it, but we must also observe that this critical elevation of dementia misses crucial aspects of the condition as a lived reality aspects which are also present in the literary works discussed. Before the next section explores a more enabling disciplinary approach to dementia, I want to point to three such limitations.

First, dementia is not only an extreme condition of cognitive impairment it is a differentiated, slow, gradual process of mental and physical decline, different stages of which require different forms of care and afford different ideas of personhood, creativity and agency. Such differentiation and pluralisation are derailed by the focus on abjection and abstraction (Burke 2019). Second, dementia requires (often mundane and unglamorous) modes of response and engagement that are not captured by the category of 'witnessing,' or by tendencies in literature and intellectual thought to elevate dementia's mental changes as a sign of its oracular, truth-generating capacities. It requires modes of attention, attachment and care that, for instance, the novels by Will Self and Emma Healey also evoke. A third problem is that Agamben's work on bare life generates an ahistorical abstraction that is not "able to address the specific historical and economic determinants that render people more or less vulnerable"; as Lucy Burke $(2019,18)$ has remarked, such an approach is decidedly unhelpful in our thinking "about the ethics and politics of long life, illness, dependency, and care." It distracts from the socioeconomic and political contexts in which we all have to deal with dementia - contexts in which the decline of the post-war welfare state, for instance, is a big issue. If dementia circulates in literary and cultural discourses of violence, it is necessary also to make visible the slow violence of diminishing welfare provisions (a reality Elizabeth Is Missing hints at, for instance, by situating its earlier murder story before the establishment of the NHS and robust welfare institutions in the UK; the decline of the welfare state is also an abiding obsession in Harstad's works). For this, an oracular capacity to stare the gloomy present in the face is arguably less useful than a readiness to tackle more mundane and unglamorous, but ultimately also more urgent, challenges. 


\section{Dementia and literary knowledge}

If literary studies wants to make a disciplinary contribution to an interdisciplinary understanding of dementia, it needs to do more than offer critical abstraction or promise empathetic relief. It is my conviction that literary studies is well equipped to throw light on the complex mental processes, intersubjective exchanges and socioeconomic ramifications of dementia. Take, as an example, this passage from the beginning of the twelfth chapter of Elizabeth Is Missing, narrated from the perspective of Maud:

Have you moved?

"No," I say, "I've been here ages."

I'm sitting in a sitting thing, for sitting on, facing a computer screen with red writing running along it: "Please make sure your GP has your new address." Every now and then there is a high-pitched beep and a name flashes across the screen [. . .] Helen [i.e. Maud's daughter] squeezes my wrist when I start to read them out loud. She is sucking on one of those strong mentholly lozenges you get for sore throats, so I suppose we must be here for her.

(Healey 2014, 152)

The passage offers a first-person perspective of a moment in the life of a person living with dementia - a perspective not available in other scientific disciplines, and not even in other artistic genres like film or documentary. Contemporary literature's update of the modernist stream of consciousness - not only in this work but also in, for instance, the so-called neuronovel (think of Mark Haddon's Curious Incident of the Dog in the Night-Time [2003], narrated from the perspective of a person with autism, or Jonathan Lethem's Motherless Brooklyn [2004], which adopts the point of view of someone with Tourette's syndrome; Roth 2009) - is a means by which it can provide otherwise unavailable fictitious insights into the workings of a mind with dementia. As readers, we share Maud's disorientation: we, like Maud, need to try to identify the disembodied voice ("Have you moved?") and make sense of objects whose names she has forgotten ("a sitting thing") and of her belief that her daughter has a sore throat, which seems to explain why she finds herself in the waiting room of a doctor's office.

Yet it would be wrong to see the passage as only an exercise in empathy (although it certainly is that). After all, the reader's disorientation in the passage is not the same as that of Maud: we, as readers, do know the name of the "sitting thing"; we do realise that the idea that Maud is still caring for her daughter rather than being fully dependent on her daughter's help is an illusion; and we do understand that the question "Have you moved?" refers to changing residence, not just changing positions. The result of this divergence is a sense of dramatic irony, creating a certain emotive distance between reader and character. Rather than 
serving as a conduit for empathy, then, literature here furnishes insight into the limits of empathetic identification. And the complexity of the novel's engagement with empathy is compounded in another way: through the repetitiveness of Maud's experience of finding her bearings, and through the frustration of seeing her forget again and again what she has just come to find out, the reader's experience of exasperation and irritation comes close to that of a typical caregiver, who faces these scenarios every day. In this way, the novel directs empathy at the disheartening plight of Helen, Maud's daughter, rather than at Maud herself (even if at other times, our sympathy for Maud increases when we suspect that her daughter is not empathetic and patient enough). The complicated interplay of alternating forms of empathy and affective distance reveals fiction to be "a site in and through which empathy is not only felt and imagined, but also negotiated and contested"; rather than providing merely an occasion for celebrating fellowfeeling, literature offers insight into "the difficulties and deficiencies in our intersubjective encounters” (Whitehead 2017, 13).

Such an insight in the complexity of understanding and feeling for people with dementia already moves beyond the uses of literature as conceptualised in the first wave of medical humanities research, in which literary feeling was called upon to compensate for the deficiencies of biomedicine. As Alan Bleakley $(2015,21)$ has argued, what literature can offer medical students is a necessary "tolerance of ambiguity," which can prevent "misdiagnoses and over-diagnoses, but also [. . .] the hierarchical structures endemic to medical culture.” Yet crucially, these insights are not only of educational or therapeutic value: the paradoxes and ambiguities of dementia, and of interactions with people with dementia, are constitutive of the phenomenon of dementia itself; they are meaningful if we want to understand the psychological, social and political dimensions of dementia. The disorienting and profoundly ambiguous encounter with a person of whom we cannot possibly know whether they know us, let alone know whether they know that we do not know whether they know us, is more similar to the engagement with a hermetic modernist poem or a Beckett play than with, say, a step-by-step diagnostic algorithm. Encounters with people with dementia take place in the contested terrain between fact and fiction, between reality and performance. In the institutional context of interdisciplinary research programmes, this is a terrain where literary studies can make a vital contribution - beyond both empathetic particularity and critical abstraction.

In Paper Minds: Literature and the Ecology of Consciousness (2018), Jonathan Kramnick has argued for an insistence on disciplinary specificity in the context of wide-ranging interdisciplinary dialogue. Every discipline, Kramnick (13) argues, partly constructs its own objects; literary dementia, for instance, is not gerontology's dementia, nor is it welfare economics' dementia: "Every discipline has its 
own expertise and its own way of explaining whatever part of the world fits with its particular interest," and true interdisciplinarity happens only "when two or more expertises join together on some project or in some conversation." The value of disciplinary specificity, then, goes hand in hand with ontological pluralism, which holds that not all phenomena can be reduced to biology and physics, and "some things are known only at their own level of explanation" (18). The world that interdisciplinary projects study, then, is "irreducibly plural” (Kramnick 2018, 21). In such a pluralist universe, literary studies can gain and contribute disciplinary specificity. Literature's capacity to imagine a first-person experience of dementia and foreground the complications of such experience allows it to articulate a kind of knowledge about dementia that can productively enter interdisciplinary dialogue.

The question remains whether Kramnick's pluralist universe finds its counterpart in pluralist universities, clinics and funding schemes. The very congruence of the movements in the field of medical humanities (towards a 'critical' interdisciplinarity), in research policy (towards an interdisciplinary focus on 'grand challenges') and within literary studies (towards affirmation), should give us pause. Kramnick notes how 'strong' interdisciplinary programmes are often legitimised through a managerial logic of innovation and disruption that simply wishes to erase disciplinary boundaries. Such "corporate silo busting," for Kramnick (2018, 24), is the academic version of broader processes of neoliberalisation that, in other sectors of society, are also eroding welfare state provisions and institutional support for, among others, people with dementia. As Lucy Burke (2017b, 2-4) has remarked, the tendency to code the rise of dementia as a "crisis," a "timebomb" or an "epidemic" emerges in a neoliberal context that reduces illness and ageing to economic costs.

To flourish in an interdisciplinary context, then, literary studies and critical theory need to be critical of interdisciplinarity's participation in a more encompassing programme that, among other things, may erode the funding for dementia care. The project of contributing to knowledge about dementia is inevitably a compromised one in a broader context that might seem to demand resistance rather than participation. Yet here also, the passage above from Elizabeth Is Missing might begin to provide useful knowledge. It shifts the focus from the interaction between doctor and patient (the "primal scene" [Whitehead and Woods 2016, 2-5] of traditional medical humanities) to the strangeness of the components making up the doctor's office environment - screens, beeps, flashes, chairs - and to Helen, the caregiver whose efforts go almost unnoticed in the novel. In this way, it begins to show that proper care provisions are not a matter of personal kindness and ethics, but a multifaceted endeavour in which many actors participate and in which infrastructure and continued investment are key. It shows that empathy is not a goal in itself; it can only circulate if welfare provisions are in place. Resisting 
the legitimisations of cuts to health care, then, is a project in which dementia patients, caregivers, scholars from various backgrounds such as neurology, geriatry and health studies, and literary scholars can find a common cause.

\section{References}

Agamben, Giorgio. Homo Sacer: Sovereign Power and Bare Life. Stanford, CA: Stanford UP, 1998.

Agamben, Giorgio. Remnants of Auschwitz: The Witness and the Archive. New York: Zone Books, 2000.

Agamben, Giorgio. "What Is the Contemporary?" What Is an Apparatus? and Other Essays. Stanford, CA: Stanford UP, 2009. 39-54.

Best, Stephen, and Sharon Marcus. "Surface Reading: An Introduction." Representations 108 (2009): 1-21.

Bleakley, Alan. Medical Humanities and Medical Education: How the Medical Humanities Can Shape Better Doctors. Abingdon: Routledge, 2015.

Burke, Lucy. "Missing Pieces: Trauma, Dementia and the Ethics of Reading in Elizabeth Is Missing." Literature and Dementia: Interdisciplinary Perspectives. Ed. Tess Maginess. Abingdon: Routledge, 2017a. 88-102.

Burke, Lucy. "Imagining a Future without Dementia: Fictions of Regeneration and the Crises of Work and Sustainability." Palgrave Communications 3.52 (2017b): 1-9.

Burke, Lucy. Dementia and the Paradigm of the Camp: Thinking beyond Giorgio Agamben's Concept of 'Bare Life.”' Journal of Bioethical Inquiry 16.2 (2019): 195-205.

Cohen, Lawrence. "Introduction: Thinking about Dementia." Thinking about Dementia: Culture, Loss, and the Anthropology of Senility. Ed. Annette Leibing and Lawrence Cohen. New Brunswick, NJ: Rutgers UP, 2006. 1-19.

De Boever, Arne. Finance Fictions: Realism and Psychosis in a Time of Economic Crisis. New York: Fordham UP, 2018.

Deleuze, Gilles, and Félix Guattari. Anti-Oedipus: Capitalism and Schizophrenia. New York: Penguin, 2009.

Doherty, Mike. "Will Self on the Literary Novel's Demise, and Why Naomi Klein Won't Fix the World.” Maclean's, 16 January 2018. https://www.macleans.ca/culture/books/will-selfon-the-literary-novels-demise-and-why-naomi-klein-wont-fix-the-world/ (14 May 2019).

Felski, Rita. The Limits of Critique. Chicago: University of Chicago Press, 2015.

Haddon, Mark. The Curious Incident of the Dog in the Night-Time. London: Jonathan Cape, 2003.

Harstad, Johan. 172 Hours on the Moon. London: Atom Books, 2012.

Healey, Emma. Elizabeth Is Missing. London: Penguin, 2014.

Jameson, Fredric. The Geopolitical Aesthetic: Cinema and Space in the World System. Bloomington: Indiana UP, 1992.

Kramnick, Jonathan. Paper Minds: Literature and the Ecology of Consciousness. Chicago: University of Chicago Press, 2018. 
Leith, Sam. "What Could Be Saner? Sam Leith on the Final Instalment of Will Self's Penetrating Consciousness Trilogy." TLS, 31 May 2017. https://www.the-tls.co.uk/articles/private/ will-self-consciousness/ (14 May 2019).

Lethem, Jonathan. Motherless Brooklyn. New York: Vintage, 2000.

Love, Heather. "Close but Not Deep: Literary Ethics and the Descriptive Turn." New Literary History 41.2 (2010): 371-391.

Maginess, Tess. Introduction. Literature and Dementia: Interdisciplinary Perspectives. Ed. Tess Maginess. Abingdon: Routledge, 2017. 1-20.

Mankell, Henning. The Troubled Man. London: Vintage Books, 2009.

Mazzucato, Mariana. Mission-Oriented Research \& Innovation in the European Union:

A Problem-Solving Approach to Fuel Innovation-Led Growth. Publication Office of the European Union. 21 February 2018. https://publications.europa.eu/en/publicationdetail/-/publication/5b2811d1-16be-11e8-9253-01aa75ed71a1/language-en (14 May 2019).

Mills, Catherine. The Philosophy of Agamben. London: Acumen, 2008.

Moretti, Franco. Signs Taken for Wonders: On the Sociology of Literary Forms. London: Verso, 2005.

Porter, Dennis. The Pursuit of Crime: Art and Ideology in Detective Fiction. New Haven, CT: Yale UP, 1981.

Robbins, Jessica. “'Older Americans' and Alzheimer’s Disease: Citizenship and Subjectivity in Contested Time." Michigan Discussions in Anthropology 17.1 (2008): 14-43.

Roth, Marco. "The Rise of the Neuronovel." N+1, 8 (2009). https://nplusonemag.com/issue-8/ essays/the-rise-of-the-neuronovel/ (6 March 2020).

Sako, Katsura. "Dementia and Detection in Elizabeth is Missing and Turn of Mind." Contemporary Women's Writing 10.3 (2016): 315-333.

Self, Will. Phone. London: Viking, 2017.

Simonsen, Peter. “'A Shadow Had Descended upon His Existence': Alzheimer's in Henning Mankell's The Troubled Man.” Post45 (2015). http://post45.research.yale.edu/2015/06/ a-shadow-had-descended-upon-his-existence-alzheimers-in-henning-mankells-thetroubled-man (14 May 2019).

Vermeulen, Pieter. "'Magnificent Desolation: The Memory of Welfare and the Archaeology of Shame in the Novels of Johan Harstad." Exploring Texts, Media, and Memory. Ed. Patrizia Lombardo, Lars Saetre and Sara Tanderup. Aarhus: Aarhus UP, 2017. 251-78.

Viney, William, Felicity Callard and Angela Woods. "Critical Medical Humanities: Embracing Entanglement, Taking Risks.” Medical Humanities 41.2 (2015): 2-7.

White, Duncan. “Will Self's Phone Is a Brilliant, Epic Anti-tweet - Review.” Telegraph, 8 June 2017. https://www.telegraph.co.uk/books/what-to-read/will-selfs-phone-brilliantepic-anti-tweet-review/ (14 May 2019).

Whitehead, Anne. Medicine and Empathy in Contemporary British Fiction: A Critical Intervention in Medical Humanities. Edinburgh: Edinburgh UP, 2017.

Whitehead, Anne, and Angela Woods. Introduction. The Edinburgh Companion to the Medical Humanities. Ed. Anne Whitehead and Angela Woods. Edinburgh: Edinburgh UP, 2016. $1-31$. 